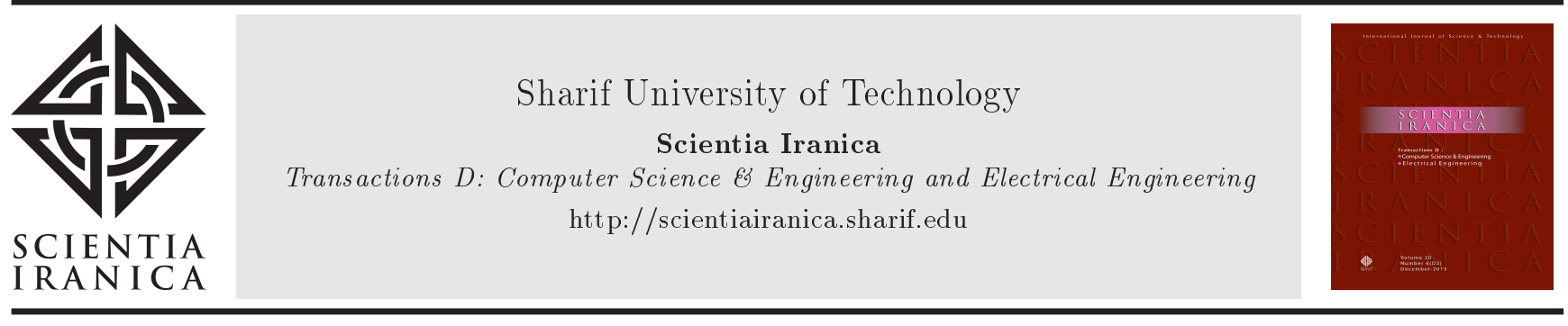

\title{
A branch-oriented active power loss allocation method for radial distribution networks with distributed generators
}

\author{
A. Prasad Hota ${ }^{a}$ and S. Mishrab ${ }^{b, *}$ \\ a. Department of Electrical Engineering, IIIT Bhubaneswar, Odisha, India. \\ b. Department of Electrical Engineering, CAPGS, BPUT, Rourkela, Odisha, India. \\ Received 15 July 2019; received in revised form 13 April 2020; accepted 1 June 2020
}

KEYWORDS
Distributed
generators;
Loss allocation;
Power flow;
Line loss;
Radial distribution
network.

KEYWORDS

Loss allocation;

Power flow;

Radial distribution

network.

\begin{abstract}
Penetration of Distributed Generation (DG) units in Radial Distribution Network (RDN) causes complexity in the case of active power Loss Allocation (LA) because it generates reverse current in the network. This current makes power system bidirectional and brings about difficulties in the decomposition of cross terms of power loss equation. To overcome such complications, this paper proposes a new branch-oriented LA technique that can eliminate the impact of mutual terms mathematically from loss formulation without any assumptions and approximations. In this respect, a direct relationship is established between the subsequent load currents of a branch and its two end voltages in terms of the complex power available at its load ends. The proposed LA scheme is found to be fair with respect to the topology of the RDN. Further, implementation of DGs may increase/decrease power loss of a system. In order to provide Distributed Generator Owners (DGOs) with the exact benefit of loss reduction, a new DG remuneration strategy is developed that assigns either rewards or penalties to DGOs following the analysis of their actual impact on system loss reduction. The effectiveness of the proposed LA method is investigated with respect to various established LA techniques using two different test systems, i.e., 17-bus and 33-bus RDNs.
\end{abstract}

(C) 2022 Sharif University of Technology. All rights reserved.

\section{Introduction}

The electrical power sector in many countries either has been deregulated or is in the process of deregulation. Consequently, several issues appear as separate generation, transmission, and distribution companies are set up rather than a single state-owned vertically

*. Corresponding author.

E-mail addresses: capgs.smishra@bput.ac.in (A. Prasad

Hota); sivmishra@gmail.com (S.Mishra)

doi: $10.24200 /$ sci.2020.53987.3546 integrated structure with the main objective of introducing competition to reduce the cost of electricity and enhance the service quality. Therefore, it is essential that various wheeling activities be clearly defined and the corresponding cost be recovered [1]. The nonlinear relationship between power loss and injected powers makes the process of Loss Allocation (LA) difficult and complicated [2]. In order to make the power system more reliable and efficient, Distributed Generations (DGs) are penetrated at the load ends. Their penetration results reverse current in the network, again bringing about difficulties in the system LA. Further, the injection of DG power may reduce the 
power loss of a system. A review of the literature shows that some established LA techniques divert a part of Network Loss Reduction (NLR) benefit to the consumer side as cross-subsidies even if their impacts on Radial Distribution Network (RDN) loss reduction are insignificant. This type of LA is unfair in terms of DG points. Hence, a proper LA scheme is to be formulated that can judiciously allocate losses among network participants with/without DGs.

Most of LA procedures existing in the literature allocate losses to Transmission Lines (TLs). Out of these procedures, a number of LA techniques are enhanced further for implementation on distribution networks. In [2], a comprehensive analysis of the characteristics of several LA methodologies was performed. Pro-Rata (PR) method [3] assigns losses to the end users as per power consumption/injection. Hence, this scheme is unfair to those customers residing close to the substation/root bus with power consumptions equal to customers connected far away. The problem associated with PR method is not found in the case of MW-mile approach [4] as it allocates losses to the network participants in terms of power consumption and geographical location. This approach performs LA by measuring the electrical distance of the load point from the substation bus and multiplying it by the power rating of the end user under consideration. Still, the above two methods execute LA without performing Load Flow (LF) calculations. Hence, this procedure may not be viable for effective practical implementation. To overcome the drawbacks as stated above, two methods namely a Newton-Raphson LFbased Direct Loss Coefficient (DLC) technique and a substitution approach of LA were introduced in [5]. DLC scheme was found unsuitable for RDNs due to its high $\mathrm{R} / \mathrm{X}$ ratio as compared to transmission systems. The total LA of Marginal/Incremental Transmission Line (M/ITL) method [6] extensively used for TLs is always higher than that of the actual loss of the system as obtained from LF calculation. Thus, the mentioned method suffers from over-recovery of losses, and to ensure the final allocation, a reconciliation procedure is applied to overcome extra losses among end users. Moreover, DLC and ITL techniques are computationally exhausted as they make use of Hessian and Jacobian matrices, respectively. The difficulties related to these computational competencies are not observed in the case of the substitution approach [5] in which the impact of network participants on system LA is evaluated individually by considering the difference between the LA results obtained from these two scenarios: when they are connected and not connected in the RDN. However, this procedure may not be recommended for fair LA as the sum of individual losses of the end-users is different from that of the net LA of the system. The network parameter-based Z- bus [7] technique widely used for LA of transmission systems is found unsuitable for overhead RDNs due to the singularity of Y-bus matrix. Thus, to allocate losses without shunt elements, Succinct Method (SM) was developed in [8]. SM establishes a linear relationship between line losses and bus-injected power under the condition that network participants maintain voltage profile within a feasible range as specified. Still, this process faces difficulties when the $X / R$ ratio of a line is higher than the $Q / P$ ratio available at its receiving end. The LA procedure discussed in [9] performs LA based on the quadratic scheme, while the method [10] uses the principle of Proportional Sharing (PS) for sharing losses among their participants. These two approaches may not be suggested for practical implementation as they assign the entire loss of the system to either loads or DG units. The above drawback is not found in the circuit-based Branch Current Decomposition Method (BCDM) [11], which has been developed from the decomposition of branch current into injected currents and node currents. However, this process is found to be delivering more spatial cross-subsidies to the consumers in the presence of DGs. A tracing-based power summation technique (PSMLA) was first introduced for power LA in the distribution network in [12] and was further extended to energy allocation through statistical analysis of daily load and generation curve in [13]. Savier and Das [14] first employed a fuzzy-based network reconfiguration technique to find an optimal network and then, used a quadratic scheme of LA to test the efficiency of the method before/after reconfiguration using several test systems. To overcome the difficulties associated with the quadratic scheme, authors in [15] employed the exact method of LA based on node voltages and injected currents to allocate losses in a balanced RDN with/without DGs. However, it remains silent regarding DG remuneration. In [16], a novel power LA scheme was proposed for the unbalanced radial power distribution system. Ghofrani-Jahromi et al. [17] presented a three-stepped LA algorithm for allocating losses to both consumers and Distributed Generator Owners (DGOs). At the first step, buses with more DG capacities than those of their load values are awarded losses. At the next step, load points having more load capacities are assigned losses compared to DGs; lastly, a reconciliation method is applied to allocate residual losses among the network participants. In [18], the traditional PR method was modified further for allocating losses at different load levels. This scheme assigns losses to end users with emphasis on their load demands and physical locations in the network. The technique developed in [19] decomposed the crossterm among the participants as per their contractual power and assigned a large amount of negative losses to the DG connected load points. Sharma and Ab- 
hyankar [20] developed a sequential LA procedure using Sequential Shapley Value (SSV) and circuit laws to allocate losses in the active RDN. This method removes time complexity and computational memory burden against Conventional Shapley Value (CSV) technique because CSV approach allocates losses after performing permutations of all the entry order of players and possible combinations. In [21], the effectiveness of the developed current summation LA technique was tested at different load levels and DG capacities where the cross-terms of Power Loss Equation (PLE) were bifurcated using logarithmic scheme. However, this scheme is subject to certain limitations, that is, the participation factors should be positive and lie within (0-2). However, this may be violated in practical RDNs due to disproportionate load or DG sizes. Kashyap and De [22] presented a PS-based LA scheme to select the optimal locations and size of the DGs in an active power network. The injected power-based LA procedure developed in [23] allocates 'zero' losses to all the DG connected load points and penalties to all DG units even if the system loss is reduced due to DG power injections. Thus, this technique does not provide justice to the DG owners. Kumar et al. [24] introduced LA scheme which decomposed the crossterm of PLE using a power factor-based LA factor; in addition, the scheme was observed to be operating efficiently in different power factor scenarios.

Various LA methods discussed above and available in the literature have precisely explained almost all the attributes essential to a fair LA. Given that power loss of a load point is very sensitive to the fluctuation of its node voltage, it is important to maintain the voltage profile stable at all the load points; otherwise, it will lead to greater system loss. Moreover, the technique used for the bifurcation of cross-term of PLE plays a significant role in system LA. Keeping this in view, this study proposes an LA method that eliminates the effect of cross-term analytically from the loss formulization without any assumptions and approximations. Moreover, a new DG remuneration technique is also developed for awarding the exact amount of NLR benefits to the DGOs after analyzing their actual contribution towards system loss reduction/enhancement. The novelty of this method can be visualized further in terms of its simplicity and capability of allocating loss among various network participants regarding their load levels, DG capacities, power factors, and geographical locations.

In light of the above issues, this study carries out the analysis further. To ensure a fair allocation, a new LA method is formulated in Section 2. Simultaneously, a DG remuneration technique is developed to provide all the benefits of NLR to DG owners in Section 2. In Section 3, the algorithms related to the proposed LA and DG remuneration schemes are presented. In order to verify the effectiveness of the proposed approach, the LA results obtained are compared and analyzed with various existing methods using two test systems (i.e., 17-bus and 33-bus) in the presence of DG units in Section 4. Finally, conclusive remarks are made in Section 5.

\section{Formulation of the proposed branch-oriented LA method}

This section comprises two subsections. The first part describes the formulation of the proposed Branch Oriented Loss Allocation (BOLA) method, while the second part deals with the development of the proposed DG remuneration technique. The proposed method uses the results of a converged power flow, as discussed in [25], for LA analysis. To include DGs into the computational process, this paper follows $\mathrm{PQ}$ type modeling instead of PV type because DG units are normally smaller in size than conventional power generators. Thus, the constant PQ model is sufficient to provide effective LF solutions for loss calculation of RDNs [26]. Further, DGs installed at load ends of a distribution system are typically not permitted to regulate the voltage; instead, they regulate power and power factor and should be modeled as negative PQ loads [27]. According to the finding of Choi and Kim [28], most of the DG units at customer sites are equipped with Automatic Voltage Regulators (AVRs) and they operate in the constant power output mode. Hence, in this scenario, the voltage output levels of the generator units remain identical to system voltages. Therefore, it is advisable to operate the interconnected nodes of DGs as PQ type in contrast to PV type. Upon keeping this in view, the negative load modeling of $\mathrm{DG}$, as discussed in [29,30], is preferred for the execution of LF and calculation of power loss in this paper. Thus, the entire calculation is carried out by considering DGs as negative constant power loads (PQ-type) throughout the LA procedure.

To make LA computation simple and easier, a unique bus identification scheme is followed in this paper. This scheme is explained by considering a sample 12-bus RDN, as shown in Figure 1. In this scheme, the substation/slack bus is numbered as ' 1 ' and the subsequent nodes along the main feeder and lateral feeders are indexed in ascending order. The branches are indexed as one unit less than those of its receiving end bus numbers, which can be verified from Figure 1. In this type of RDN, the total Number of Buses (NB) and Branches (NBR) is related as follows:

$$
N B R=N B-1
$$

To avoid conflict between the complex operator ' $j$ ' and branch $j$, the branch $j$ is represented as branch 


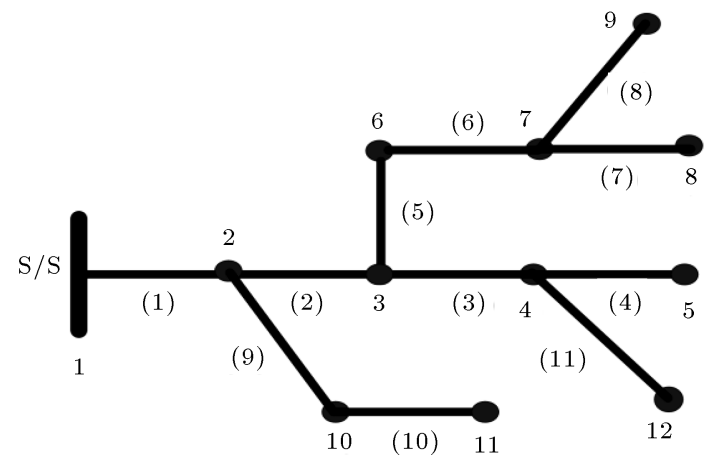

Figure 1. A sample of the 12-bus radial distribution network.

$j j$ in this study. For easier identification of nodes and faster calculation, several arrays are proposed for storing information related to the adjacent (Figure 2), subsequent (Figure 3), and previous buses (Figure
2) of the RDN. An array $a d b[$ ] of dimension twice that of NBR is used for storing adjacent network buses. Further, arrays of two pointers $m f[]$ and $m t$ [ ] characterized by the dimension equal to NB are proposed to locate the initial and final memory locations of the adjacent buses relevant to a particular node in the network, respectively. The operations of the above arrays are described here through node 4 (i.e., $a=4$ ) of the 12-bus RDN. According to Figure 1, this node has three adjacent buses: Nodes 3, 5, and 12 , which are stored in the array $a d b[]$ within the memory locations of 8 to 10 . The initial memory location ' $s=8$ ' can be fetched from the array $m f[]$ as $s=m f(a)=m f(4)=8$. With this value of $s$, the first adjacent node ' 3 ' can be identified in the array $a d b[]$ as $a d b(s)=a d b(8)=3$ (Figure 2). In a similar manner, the last adjacent node ' 12 ' can be accessed using $m t$ [ ] array as: $a d b(s)=a d b\{m t(4)\}=a d b(10)=12$. Once

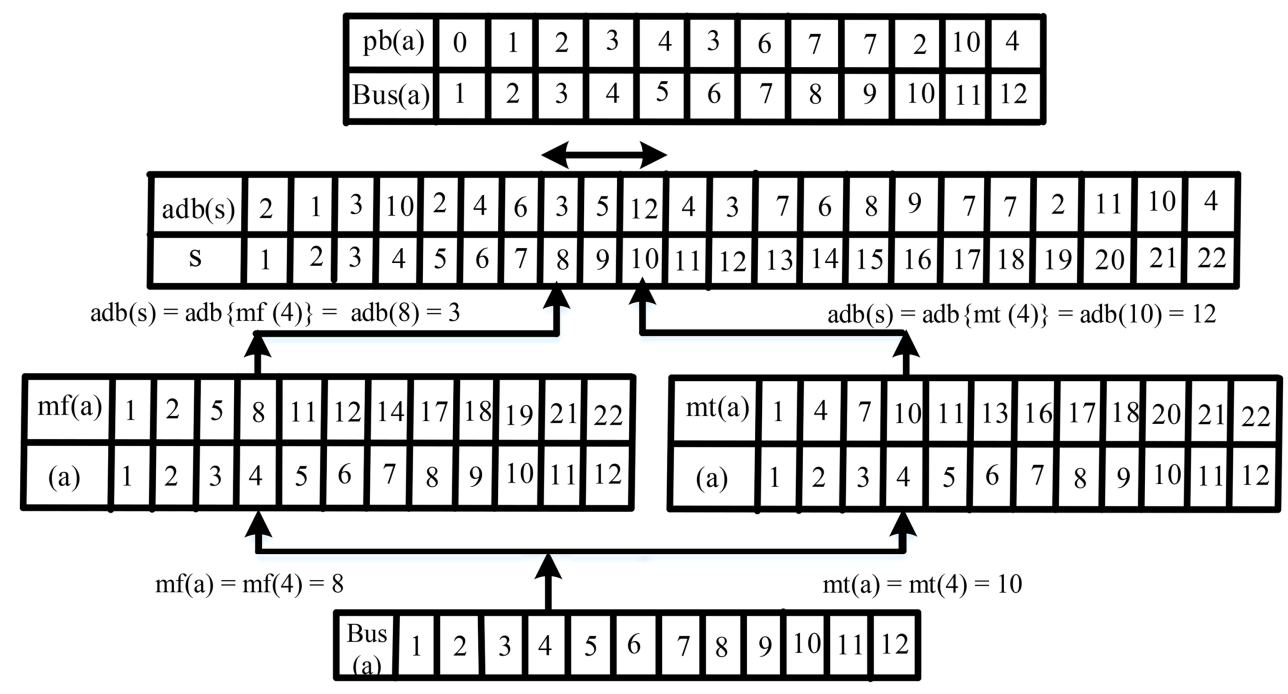

Figure 2. Contents of $m f[], m t[], a d b[]$, and $p b[]$ arrays of the 12-bus radial distribution network.

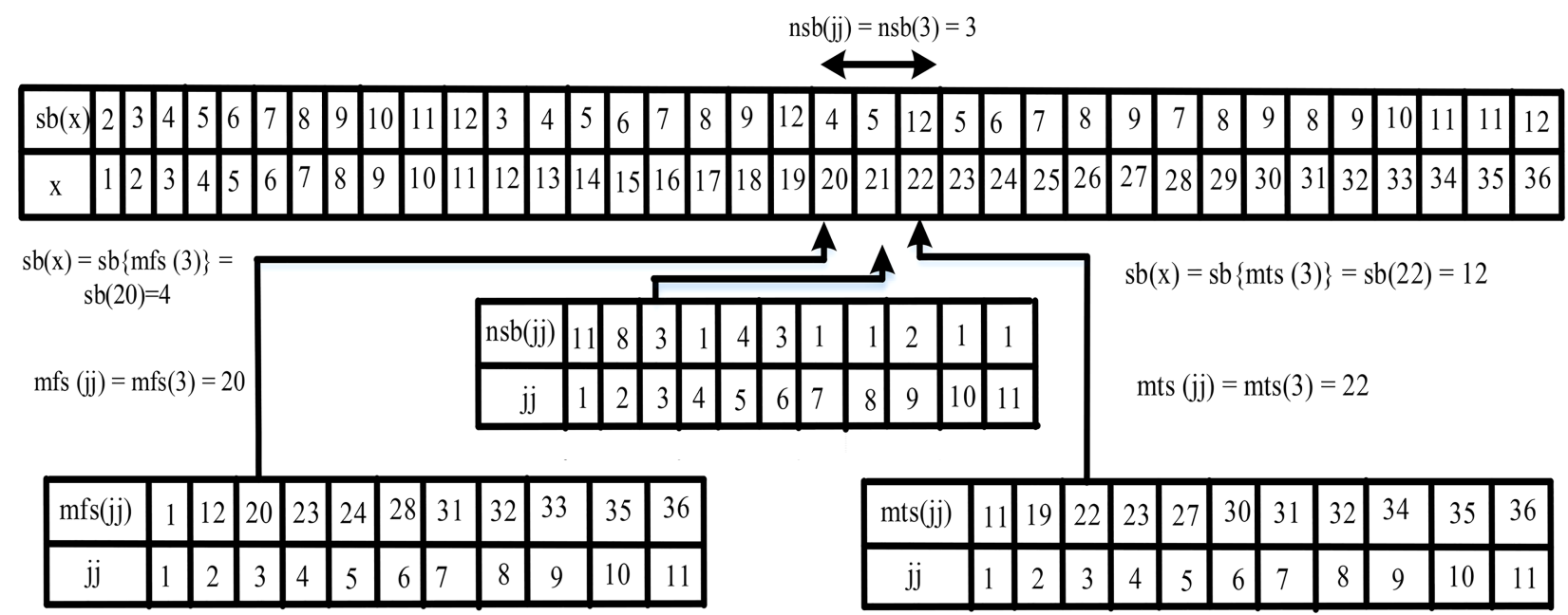

Figure 3. Contents of $m f s[], m t s[], s b[]$, and $n s b[]$ arrays of the 12-bus radial distribution network. 
the initial and final memory locations of the adjacent buses corresponding to a node in the array $a d b[$ ] are known, other values can be traced within these locations as discussed above. Hence, adjacent buses relating to each node of the RDN can be identified in a similar fashion. Moreover, an array $p b[$ ] of dimension equal to is used to store the previous bus information corresponding to each node of the RDN. The previous bus of node 4 can be fetched from this array as $p b(a)=$ $p b(4)=3$, which can be verified from Figure 2 .

Similarly, two other arrays $n s b[]$ and $s b[$ ] are proposed to store the information related to the subsequent buses corresponding to each branch of the RDN. Two pointer arrays, $m f s[]$ and $m t s[]$, of dimension equal to NB are proposed to locate the initial and final memory locations of the subsequent buses related to a particular branch $j j$ in the network, respectively. The subsequent bus information of the considered 12-bus system is provided in Figure 3. The operations of the above arrays are explained here through branch 3 (i.e., $j j=3$ ) of the 12 bus RDN. According to Figure 1, this branch has three subsequent buses namely nodes 4,5 , and 12 that are stored in the array $s b[]$ in the memory locations (20 to 22 ). The initial memory location ' $x=20$ ' can be fetched from the array $m f s[$ ] as $x=m f s(j j)=m f s(3)=20$. With this value of $x$, the first subsequent node ' 4 ' can be identified in the array $s b[]$ as $s b(x)=s b(20)=4$. In a similar fashion, the last subsequent node ' 12 ' can be accessed using $m t s[$ ] array as: $s b(x)=s b\{m t s(3)\}=s b(22)=12$. Once the initial and final memory locations of the subsequent buses corresponding to a branch in the array $s b[$ are known, other values can be traced within these locations, as discussed above. Thus, subsequent buses related to each branch of the RDN can be identified in a similar fashion. The number of subsequent buses corresponding to each branch of the RDN is counted and stored in the array $n s b[]$. The formations of these arrays are made using the network data and simple programming techniques in the MATLAB-R2018b environment.

\subsection{Proposed LA scheme}

The Equivalent Current Injection (ECI) at a particular node ' $a$ ' (Figure 4 ) with complex power load $S_{L a}=$ $P_{L a}+j Q_{L a}$ and node voltage $V_{a}$ can be calculated as follows:

$$
I_{L a}=\frac{\left(P_{L a}-j Q_{L a}\right)}{V_{a}^{*}}, \quad a=2,3, \ldots, N B .
$$

The current of any branch $j j$ can be computed in terms of its subsequent load currents $\left(I_{L a}\right)$ using the arrays $m f s[], m t s[]$, and $s b[]$ as follows:

$$
I(j j)=\sum_{a=s b(m f s(j j))}^{s b(m t s(j j))} I_{L a} .
$$

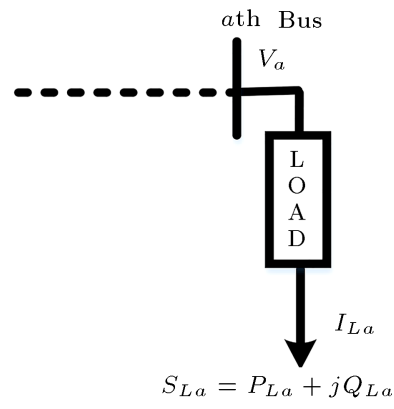

Figure 4. Equivalent current injection at bus a of the radial distribution network.

By using Eq. (3) and rewriting Eq. (2), the current of branch $j j$ can be expressed in terms of complex power as follows:

$$
I(j j)=\sum_{a=s b(m f s(j j))}^{s b(m t s(j j))} \frac{P_{L a}-j Q_{L a}}{V_{a}^{*}} .
$$

Thus, the active power loss of a branch $j j$ can be evaluated as follows:

$$
P L o s s(j j)=\operatorname{Real}\left[\left(V_{s}-V_{r}\right)^{*} \cdot I(j j)\right],
$$

where $V_{s}, V_{r}$, and $I(j j)$ are the sending end voltage, receiving end voltage, and current of branch ' $j j$ ', respectively.

Upon substituting Eq. (4) into Eq. (5), the PLE can be expressed as follows:

$$
\begin{aligned}
& \operatorname{PLoss}(j j)=\text { Real } \\
& \left.\qquad\left(V_{s}-V_{r}\right)^{*} \cdot \sum_{a=s b(m f s(j j))}^{s b(m t s(j j))} \frac{P_{L a}-j Q_{L a}}{V_{a}{ }^{*}}\right] .
\end{aligned}
$$

Rearranging, we have:

$$
\begin{aligned}
& \operatorname{PLoss}(j j)=\operatorname{Re} a l \\
& \left.\qquad \sum_{a=s b(m f s(j j))}^{s b(m t s(j j))}\left(\frac{V_{s}-V_{r}}{V_{a}}\right)^{*} \cdot\left(P_{L a}-j Q_{L a}\right)\right] .
\end{aligned}
$$

Let:

$$
\left(\frac{V_{s}-V_{r}}{V_{a}}\right)^{*}=X(a)+j Y(a) .
$$

The real power loss of branch $j j$ is then represented as follows:

$$
\operatorname{PLoss}(j j)=\sum_{a=s b(m f s(j j))}^{s b(m t s(j j))} X(a) P_{L a}+Y(a) Q_{L a} .
$$

Thus, it can be concluded from Eq. (8) that the power loss of branch $j j$ is allocated among the consumers 
present beyond branch $j j$. Therefore, the loss share of each subsequent consumer of branch $j j$ can be computed as follows:

$$
P \operatorname{Loss}(j j, a)=X(a) P_{L a}+Y(a) Q_{L a} .
$$

Total LA to a consumer connected at node is calculated by adding its individual loss shares to each of branches $j j$ of the RDN using Eq. (9) and is given as follows:

$$
\text { TPLoss }(a)=\sum_{j j=1}^{N B-1} P \operatorname{Loss}(j j, a) \text {. }
$$

Hence, the total power loss of the RDN can be evaluated by adding the power loss of the individual nodes as follows:

$$
\text { TPLoss }=\sum_{a=1}^{N B} \text { TPLoss }(a) \text {. }
$$

\subsection{Proposed DG remuneration technique}

Based on a review of the literature, the power loss of a system is reduced by connecting DG units to the system. Thus, a fair LA method should provide DGOs with all the benefits of loss reduction as per their individual participation towards NLR. However, it has been observed that some LA schemes $[11,17,18]$ have diverted a part of NLR to the consumer side as crosssubsidies even if their impact on NLR is insignificant, which is unfair to the DGOs. However, this drawback is eliminated in the case of the proposed remuneration technique by allocating losses to DG units after analyzing their individual contributions to system loss reduction. The detailed procedure of DG remuneration scheme is presented below. Here, Eq. (12) represents the total loss of the RDN in the absence of DG units. When DGs are connected, RDN loss is reduced due to the flow of reverse current in the network. Hence, in this condition, LF is carried out considering DGs as negative loads and power loss of the RDN is evaluated through the proposed LA formulation, as provided in Eq. (13). To determine the contributions of DG units towards NLR, the total losses of the RDN obtained in the above two scenarios, i.e., without and with DGs, are subtracted, as shown in Eq. (14). Thus, without DGs, the active power loss of the RDN is computed using Eq. (11) as follows:

$$
P_{a d g}=\sum_{a=1}^{N B} T P \operatorname{Loss}(a) .
$$

Further, the real power loss of the RDN with all DGs is calculated as follows:

$$
P_{p d g}=\sum_{a=1}^{N B} T P \operatorname{Loss}(a) \text {. }
$$

Total NLR due to DGs can be evaluated through Eqs. (12) and (13) as follows:

$$
P_{d g s}=P_{a d g}-P_{p d g} .
$$

The total system loss $\left(p_{d g}(p)\right)$ without $(p$ th) DG unit is calculated by connecting the remaining $\left(N_{d g}-1\right)$ numbers of DGs in the RDN using the power loss in Eq. (11). Thus, the contribution (i.e., $\left.I n_{d g}(p)\right)$ of an individual DG unit (i.e., $p$ th) can be evaluated as follows:

$$
\operatorname{In}_{d g}(p)=P_{d g}(p)-P_{d g s},
$$

where $I n_{d g}$ represents the remuneration allotted to the $p$ th DG Owner and $N_{d g}$ the total number of DG connected in the RDN.

$$
\operatorname{TIn} n_{d g}=\sum_{p=1}^{N_{d g}} \operatorname{In}_{d g}(p) \text {. }
$$

It is important to note that legacy distribution systems are radial in structure and there is a clear variation in node voltages from the source end to the tail end. Therefore, there may be a small variation between the values of $P_{d g s}$ and $T I n_{d g}$ at constant power type load due to the variation in node voltages during power flow calculation. However, this variation can be reduced to an insignificant value by injecting numerous DGs into the system, as strategically well-located DG units provide adequate voltage support for the system [31]. Thus, by keeping this aspect in mind, a small difference is expressed in Eq. (17) in case it exists; then, this amount of difference is to be distributed among the DGOs as per their proportional contribution in the exciting remuneration, as shown in Eq. (18). Hence, the difference in remuneration and its fair allocation is performed as follows:

$$
\operatorname{Diff}\left(\operatorname{In}_{d g}\right)=P_{d g s}-\operatorname{TIn}_{d g} .
$$

Thus, the final remuneration provided for the $p$ th DG owner is:

$$
f \operatorname{In}_{d g}(p)=\operatorname{In}_{d g}(p)+\left[\operatorname{Diff}\left(\operatorname{In}_{d g}\right) \times\left\{\frac{\operatorname{In}_{d g}(p)}{T I n_{d g}}\right\}\right] \text {. }
$$

Hence, the final remuneration allocated to all the DG owners is computed as follows:

$$
f T I n_{d g}=\sum_{p=1}^{N_{d g}} f \operatorname{In}_{d g}(p)
$$

To determine the effectiveness of the proposed remuneration technique, the total remuneration allocated to DGOs by Eq. (19) is compared with the value of $P_{d g s}$, which is found equal in both of the case studies: Cases I and II, which can be verified from Section 4 . 


\section{Algorithms of the proposed methods}

\subsection{Algorithm of the proposed LA technique}

Step 1: Use network data of the RDN to form the arrays $n s b, s b, m t, m f$, adb, mts, $m f s$, and $p b$.

Step 2: Initialize all branch losses to ' 0 ' and all node voltages to ' $1 p . u$ ' (magnitude) with angle '0 radian';

Step 3: Initialize the iteration counter from ' 0 ' and set the tolerance to ' 0.0001 ';

Step 4: Evaluate ECI of all the load points using Eq. (2);

Step 5: Use $m f s, m t s$ and $s b$ arrays to calculate all the branch currents through Eq. (3);

Step 6: Initialize $i=2$;

Step 7: Update node voltages using forward sweep technique. Identify bus $n$ (i.e., previous to bus- $i$ ) and place it in array $p b(i)$. The voltage of the $i$ th load point is then updated by utilizing the circuit data of the $(i-1)$ th branch and voltage of the $n$th load point;

Step 8: Update $i=i+1$;

Step 9: If $i=\mathrm{NB}$, proceed to Step 10; else, take Step 7;

Step 10: Increase the iteration counter by one unit;

Step 11: Check the convergence criterion by comparing the newly obtained node voltage values with the previous iteration. If it is satisfied, proceed to Step 12; else, take Step 4;

Step 12: Evaluate power loss of all the branches and total power loss of the network;

Step 13: Initialize total LA of each load point to zero, i.e., $\operatorname{TPLoss}(a)=0, a=2,3, \ldots, \mathrm{NB}$;

Step 14: Set the value of ' $i$ ' to ' 2 ';

Step 15: Search for the previous load point of node $i$ as $n=p b(i)$ and then, estimate $\left(V_{r}-V_{i}\right)$;

Step 16: Search the subsequent nodes corresponding to the $(i-1)$ th branch from $s b[]$ array and distribute power loss of this branch among the subsequent load points using Eq. (9);

Step 17: Update $i=i+1$ and check if $i=\mathrm{NB}$; then, follow Step 18; else, proceed to Step 15;

Step 18: Evaluate the total loss assigned to each of the end users using Eq. (10).

\subsection{Algorithm of the proposed DG remuneration technique}

Step 1: Compute the total power loss of the RDN (TPLoss) in the absence of DG units using Eq. (12);

Step 2: Perform LF and calculate total power loss of the RDN (TPLoss) in the presence of all DG units using Eq. (13);
Step 3: Calculate total remuneration $\left(P_{d g s}\right)$ to be provided for the DGOs in (kW) due to loss reduction in the network using Eq. (14);

Step 4: Calculate the loss reduction by an individual DG unit (i.e., $\left.I n_{d q}(p)\right)$ as the difference between the LA of all DGs (i.e., $\left.P_{d g s}\right)$ and $\left(N_{d g}-1\right)$ numbers of DGs (i.e., $\left.P_{d g}(p)\right)$ regardless of the DG unit (i.e., $p$ th DG) whose remuneration is to be calculated;

Step 5: Provide the remuneration for the $p$ th DG owner according to Eq. (15);

Step 6: Compute the remuneration to be awarded to each DG unit utilizing the above two steps;

Step 7: Evaluate final remuneration $\left(T I n_{d g}\right)$ awarded to the DG owners by adding all $I n_{d g}(p)$ 's, where $p=1,2,3, \ldots, N_{d g}$;

Step 8: Check that Diff $\left(I n_{d g}\right)=0$; if yes, proceed to Step 9; else, go to Step 10;

Step 9: The reward provided for the $p$ th DG owner is equal to $I n_{d g}(p)$;

Step 10: Calculate the final remuneration awarded to the $p$ th DGO using Eq. (18).

\section{Results and discussion}

In this section, the effectiveness of the proposed BOLA technique is investigated against various established LA methods using two different test systems (i.e., 17bus and 33-bus systems). The detailed line data of these two test systems are provided in Table 1. The corresponding load and DG data along with comparative LA results of 17 -bus and 33-bus test systems are represented in Tables 2 and 3, respectively. The LF and power loss analysis was carried out by considering DGs as negative loads throughout the computational process. In the LA process, positive values are treated as penalties and negative values as rewards to the participants. All the simulations are performed using a system having the following configuration: Intel $(\mathrm{R})$ Core(TM) i3-6006U processor, $2 \mathrm{GHz}$ CPU, 8 GB RAM, and Windows 10 operating system.

\subsection{Case study I (a 17-bus test system)}

A $20 \mathrm{kV}, 17$-bus RDN [20] composed of 12 load points, 3 DG units, and 16 lines is first considered for the implementation of the proposed scheme. The location and size of DG units are finalized as per paper [23]. Thus, three DGs are selected to be placed at nodes 15 , 16, and 17 whose details are provided in Table 2 . It is observed that without DGs, the total active power loss of the system is $22.74 \mathrm{~kW}$ and is reduced to $6.64 \mathrm{~kW}$ due to the injection of $\mathrm{DG}$ power into the system. Thus, the total NLR of $16.10 \mathrm{~kW}$ occurs due to the penetration of DGs into the RDN. The present approach of LA is contemporary and comparable to 
Table 1. Detailed line data of 17 and 33-bus test systems.

\begin{tabular}{|c|c|c|c|c|c|}
\hline \multicolumn{6}{|c|}{ Line data of 17 and 33 bus distribution systems } \\
\hline \multicolumn{6}{|c|}{ Data of 17 -bus system } \\
\hline $\begin{array}{l}\text { Sending end } \\
\text { node }\end{array}$ & $\begin{array}{c}\text { Receiving end } \\
\text { node }\end{array}$ & Branch no. & $\begin{array}{c}\text { Resistance of } \\
\text { the branch } \\
\text { (pu) }\end{array}$ & $\begin{array}{c}\text { Reactance of } \\
\text { the branch } \\
\text { (pu) }\end{array}$ & $\begin{array}{c}\text { Charging } \\
\text { capacitance } \\
(\mathrm{pu})\end{array}$ \\
\hline 1 & 2 & 1 & 0.0025 & 0.0026 & 0.03 \\
\hline 2 & 3 & 2 & 0.0008 & 0.0008 & 0.02 \\
\hline 3 & 4 & 3 & 0.0007 & 0.0007 & 0.02 \\
\hline 2 & 5 & 4 & 0.0007 & 0.0007 & 0 \\
\hline 5 & 6 & 5 & 0.002 & 0.0021 & 0.02 \\
\hline 6 & 7 & 6 & 0.0009 & 0.0009 & 0.01 \\
\hline 7 & 8 & 7 & 0.0017 & 0.0017 & 0.01 \\
\hline 5 & 9 & 8 & 0.0021 & 0.0022 & 0.02 \\
\hline 6 & 10 & 9 & 0.0001 & 0.0001 & 0 \\
\hline 10 & 11 & 10 & 0.0006 & 0.0006 & 0 \\
\hline 10 & 12 & 11 & 0.0018 & 0.0018 & 0 \\
\hline 12 & 13 & 12 & 0.0003 & 0.0003 & 0 \\
\hline 12 & 14 & 13 & 0.0011 & 0.0011 & 0 \\
\hline 14 & 15 & 14 & 0.0011 & 0.0011 & 0 \\
\hline 15 & 16 & 15 & 0.0001 & 0.0001 & 0 \\
\hline 14 & 17 & 16 & 0.0007 & 0.0007 & 0 \\
\hline- & - & - & - & - & - \\
\hline- & - & - & - & - & - \\
\hline- & - & - & - & - & - \\
\hline- & - & - & - & - & - \\
\hline- & - & - & - & - & - \\
\hline- & - & - & - & - & - \\
\hline- & - & - & - & - & - \\
\hline- & - & - & - & - & - \\
\hline- & - & - & - & - & - \\
\hline- & - & - & - & - & - \\
\hline- & - & - & - & - & - \\
\hline- & - & - & - & - & - \\
\hline- & - & - & - & - & - \\
\hline- & - & - & - & - & - \\
\hline- & - & - & - & - & - \\
\hline- & - & - & - & - & - \\
\hline
\end{tabular}


Table 1. Detailed line data of 17 and 33-bus test systems (continued).

\begin{tabular}{|c|c|c|c|c|}
\hline \multicolumn{5}{|c|}{ Line data of 17 and 33 bus distribution systems } \\
\hline \multicolumn{5}{|c|}{ Data of 33-bus system } \\
\hline $\begin{array}{l}\text { Sending end } \\
\text { node }\end{array}$ & $\begin{array}{l}\text { Receiving end } \\
\text { node }\end{array}$ & Branch no. & $\begin{array}{c}\text { Resistance of } \\
\text { the branch } \\
(\Omega)\end{array}$ & $\begin{array}{c}\text { Reactance of } \\
\text { the branch } \\
(\Omega)\end{array}$ \\
\hline 1 & 2 & 1 & 0.0922 & 0.047 \\
\hline 2 & 3 & 2 & 0.493 & 0.2511 \\
\hline 3 & 4 & 3 & 0.366 & 0.1864 \\
\hline 4 & 5 & 4 & 0.3811 & 0.1941 \\
\hline 5 & 6 & 5 & 0.819 & 0.707 \\
\hline 6 & 7 & 6 & 0.1872 & 0.6188 \\
\hline 7 & 8 & 7 & 0.7114 & 0.2351 \\
\hline 8 & 9 & 8 & 1.03 & 0.74 \\
\hline 9 & 10 & 9 & 1.044 & 0.74 \\
\hline 10 & 11 & 10 & 0.1966 & 0.065 \\
\hline 11 & 12 & 11 & 0.3744 & 0.1238 \\
\hline 12 & 13 & 12 & 1.468 & 1.155 \\
\hline 13 & 14 & 13 & 0.5416 & 0.7129 \\
\hline 14 & 15 & 14 & 0.591 & 0.526 \\
\hline 15 & 16 & 15 & 0.7463 & 0.545 \\
\hline 16 & 17 & 16 & 1.289 & 1.721 \\
\hline 17 & 18 & 17 & 0.732 & 0.574 \\
\hline 2 & 19 & 18 & 0.164 & 0.1565 \\
\hline 19 & 20 & 19 & 1.5042 & 1.3554 \\
\hline 20 & 21 & 20 & 0.4095 & 0.4784 \\
\hline 21 & 22 & 21 & 0.7089 & 0.9373 \\
\hline 3 & 23 & 22 & 0.4512 & 0.3083 \\
\hline 23 & 24 & 23 & 0.898 & 0.7091 \\
\hline 24 & 25 & 24 & 0.896 & 0.7011 \\
\hline 6 & 26 & 25 & 0.203 & 0.1034 \\
\hline 26 & 27 & 26 & 0.2842 & 0.1447 \\
\hline 27 & 28 & 27 & 1.059 & 0.9337 \\
\hline 28 & 29 & 28 & 0.8042 & 0.7006 \\
\hline 29 & 30 & 29 & 0.5075 & 0.2585 \\
\hline 30 & 31 & 30 & 0.9744 & 0.963 \\
\hline 31 & 32 & 31 & 0.3105 & 0.3619 \\
\hline 32 & 33 & 32 & 0.341 & 0.5302 \\
\hline
\end{tabular}


Table 2. Load/DG data and loss allocation results of a 17-bus test system.

\begin{tabular}{|c|c|c|c|c|c|c|c|c|c|c|c|}
\hline \multirow[b]{3}{*}{ Bus no. } & \multicolumn{10}{|c|}{ Loss allocation of 17 -bus distribution system (in $\mathrm{kW}$ ) } & \multirow[b]{3}{*}{$\begin{array}{c}\text { Method } \\
{[23]}\end{array}$} \\
\hline & \multicolumn{2}{|c|}{ Load/generation at nodes } & \multicolumn{8}{|c|}{ Loss Allocation at various nodes by different methods } & \\
\hline & $\begin{array}{c}\mathbf{P} \\
(\mathrm{kW})\end{array}$ & $\begin{array}{c}\mathrm{Q} \\
(\mathrm{kVAR})\end{array}$ & $\begin{array}{c}\text { Proposed } \\
\text { method }\end{array}$ & $\begin{array}{c}\text { PR } \\
\text { method } \\
{[3]} \\
\end{array}$ & $\begin{array}{c}\text { Marginal } \\
\text { method } \\
{[5]}\end{array}$ & $\begin{array}{c}\text { Z-bus } \\
\text { method } \\
{[7]}\end{array}$ & $\begin{array}{c}\text { SM } \\
\text { method } \\
{[8]} \\
\end{array}$ & $\begin{array}{c}\text { BCDM } \\
\text { method } \\
{[11]}\end{array}$ & $\begin{array}{c}\text { Jahromi's } \\
\text { method } \\
{[17]}\end{array}$ & $\begin{array}{c}\text { SSV } \\
\text { method } \\
{[20]}\end{array}$ & \\
\hline 1 & 0.00 & 0.00 & 0.00 & 0.00 & 0.00 & 0.00 & 0.00 & 0.00 & 0.00 & 0.00 & 0.00 \\
\hline 2 & 0.00 & 0.00 & 0.00 & 0.00 & 0.00 & 0.00 & 0.00 & 0.00 & 0.00 & 0.00 & 0.00 \\
\hline 3 & 89.00 & 50.00 & 0.36 & 0.16 & 0.34 & 0.22 & 0.22 & 0.33 & 0.09 & 0.33 & 0.08 \\
\hline 4 & 111.00 & 63.00 & 0.46 & 0.2 & 0.49 & 0.29 & 0.29 & 0.43 & 0.18 & 0.42 & 0.16 \\
\hline 5 & 140.00 & 80.00 & 0.67 & 0.25 & 0.56 & 0.43 & 0.44 & 0.62 & 0.26 & 0.60 & 0.27 \\
\hline 6 & 0.00 & 0.00 & 0.00 & 0.00 & 0.00 & 0.00 & 0.00 & 0.00 & 0.00 & 0.00 & 0.00 \\
\hline 7 & 141.00 & 80.00 & 1.02 & 0.25 & 0.52 & 0.78 & 0.79 & 0.96 & 0.87 & 0.93 & 0.81 \\
\hline 8 & 338.00 & 192.00 & 2.61 & 0.6 & 2.08 & 2.12 & 2.15 & 2.56 & 3.39 & 2.49 & 3.24 \\
\hline 9 & 89.00 & 50.00 & 0.44 & 0.16 & 0.49 & 0.30 & 0.3 & 0.41 & 0.16 & 0.40 & 0.18 \\
\hline 10 & 0.00 & 0.00 & 0.00 & 0.00 & 0.00 & 0.00 & 0.00 & 0.00 & 0.00 & 0.00 & 0.00 \\
\hline 11 & 152.00 & 86.00 & 1.06 & 0.27 & 0.37 & 0.77 & 0.79 & 0.97 & 1.24 & 0.94 & 1.13 \\
\hline 12 & 266.00 & 151.00 & 1.71 & 0.49 & -0.30 & 1.37 & 1.42 & 1.70 & 0.39 & 1.67 & 0.42 \\
\hline 13 & 10.00 & 5.00 & 0.07 & 0.02 & -0.03 & 0.05 & 0.05 & 0.06 & 0.01 & 0.06 & 0.01 \\
\hline 14 & 0.00 & 0.00 & 0.00 & 0.00 & 0.00 & 0.00 & 0.00 & 0.00 & 0.00 & 0.00 & 0.00 \\
\hline 15 & 205.00 & 116.00 & -0.68 & 0.37 & -1.98 & -0.25 & -0.15 & 1.05 & 0.00 & 1.16 & 0.00 \\
\hline 16 & 72.00 & 41.00 & -0.89 & 0.13 & -0.80 & -0.09 & -0.06 & 0.39 & 0.00 & 0.40 & 0.00 \\
\hline 17 & 241.00 & 137.00 & -0.19 & 0.43 & -2.14 & -0.51 & -0.18 & 0.72 & 0.00 & 1.42 & 0.00 \\
\hline DG15 & 300.00 & 145.29 & -6.83 & 1.31 & 2.79 & 0.37 & 0.22 & -1.53 & 0.03 & -1.62 & 0.16 \\
\hline DG16 & 200.00 & 96.86 & -3.52 & 0.87 & 2.10 & 0.24 & 0.17 & -1.08 & 0.02 & -1.08 & 0.11 \\
\hline DG17 & 260.00 & 125.92 & -5.76 & 1.13 & 2.15 & 0.55 & 0.19 & -0.78 & 0.00 & -1.48 & 0.07 \\
\hline \multicolumn{3}{|c|}{ Total loss } & 6.64 & 6.64 & 6.64 & 6.64 & 6.64 & 6.64 & 6.64 & 6.64 & 6.64 \\
\hline
\end{tabular}

Note: P: Active power; Q: Reactive power; DG: Distributed Generator; PR: Pro-Rata method; SM: Succinct Method;

BCDM: Branch Current Decomposition Method; SSV: Sequential Shapley Value method.

other established methods (PR [3], Marginal [5], Zbus [7], SM [8], BCDM [11], Jahromi's method [17], SSV [20], and Method [23]) as the final allocation of the RDN remains the same with/without DGs.

According to Table 2, PR method [3] assigns losses to its network participants as per their load demands. Thus, consumers of equal ratings connected close to the substation bus (e.g., consumer at node 3 ) are assigned an equal number of losses as that of the consumers placed far away (e.g., consumer at node 9 ). Moreover, this method assigns penalties to the DGs even if their presence reduces system loss in the network, which is again unfair to the DGOs. Hence, PR approach may not be suggested for fair LA as it assigns losses to the network participants without considering their geographical locations. In contrast, the proposed technique takes care of these issues and provides DGOs with all the benefits of loss reduction as per actual contribution to NLR. The DG-connected node 15 is getting the highest remuneration of $6.83 \mathrm{~kW}$ as it delivers maximum power to the system. Similarly, the generator at node 17 is rewarded more $(5.76 \mathrm{~kW})$ than that at node $16(3.52 \mathrm{~kW})$. Thus, the present method considers a judicious approach of LA and DG remuneration.

The ITL-based marginal approach [5] provides high volatility and assigns negative losses to the network participants. Instead of giving incentives, huge losses are assigned to DGs, which is undesired. Also, it suffers from the LA imbalance between demand and generation sides, as observed from Table 2. It can be observed that the DGOs are assigned high values of positive losses, while the consumers at nodes 12 , 13, and 15-17 are allocated large amounts of negative losses. In contrast, the proposed method provides a small incentive for the DG-connected nodes due to the reverse current effect and maximum benefit to the generation side, which is acceptable. Moreover, the 
Table 3. Load/DG data and loss allocation results of a 33-bus test system.

\begin{tabular}{|c|c|c|c|c|c|c|c|c|c|c|}
\hline \multicolumn{11}{|c|}{ Loss allocation of 33 -bus distribution system $(\mathrm{kW})$} \\
\hline \multirow[b]{2}{*}{ Bus no. } & \multicolumn{2}{|c|}{$\begin{array}{c}\text { Load/generation } \\
\text { at nodes }\end{array}$} & \multicolumn{8}{|c|}{ Loss allocation at various nodes by different loss allocation methods } \\
\hline & $\begin{array}{c}\mathbf{P} \\
(\mathrm{kW})\end{array}$ & $\begin{array}{c}\mathrm{Q} \\
(\mathrm{kVAR})\end{array}$ & $\begin{array}{l}\text { Proposed } \\
\text { method }\end{array}$ & $\begin{array}{c}\text { MLC } \\
\text { method } \\
{[5]}\end{array}$ & $\begin{array}{c}\text { BCDM } \\
\text { method } \\
{[11]}\end{array}$ & $\begin{array}{c}\text { PSMLA } \\
\text { method } \\
{[12]}\end{array}$ & $\begin{array}{c}\text { Ghaemi's } \\
\text { method } \\
{[19]}\end{array}$ & $\begin{array}{c}\text { Branch } \\
\text { oriented } \\
\text { PR method } \\
{[18]}\end{array}$ & $\begin{array}{c}\text { Voltage } \\
\text { based } \\
\text { LA } \\
{[18]}\end{array}$ & $\begin{array}{c}\text { Proportional } \\
\text { method } \\
{[10]}\end{array}$ \\
\hline 1 & 0 & 0 & 0 & 0 & 0 & 0 & 0 & 0 & 0 & 0 \\
\hline 2 & 100 & 60 & 0.07 & 0.03 & 0.05 & 0.2 & 0.17 & 0.07 & 0.07 & 0.19 \\
\hline 3 & 90 & 40 & 0.24 & 0.1 & 0.12 & 0.81 & 0.73 & 0.23 & 0.22 & 0.83 \\
\hline 4 & 120 & 80 & 0.53 & 0.17 & 0.26 & 2.49 & 1.91 & 0.5 & 0.51 & 2.17 \\
\hline 5 & 60 & 30 & 0.26 & 0.08 & 0.07 & 0.77 & 0.82 & 0.24 & 0.25 & 0.93 \\
\hline 6 & 60 & 20 & -12.7 & 0.06 & -0.05 & 1.05 & -53.66 & 0.24 & 0.27 & 1.28 \\
\hline 7 & 200 & 100 & 1.6 & 0.41 & 0.35 & 11.06 & 10.08 & 1.48 & 1.59 & 8.14 \\
\hline 8 & 200 & 100 & 2.6 & 0.97 & 1.34 & 12.73 & 10.08 & 2.48 & 2.58 & 9.53 \\
\hline 9 & 60 & 20 & 1.05 & 0.45 & 0.61 & 1.56 & 1.91 & 1.01 & 1.04 & 1.87 \\
\hline 10 & 60 & 20 & 1.37 & 0.62 & 0.91 & 1.81 & 2.15 & 1.33 & 1.38 & 2.15 \\
\hline 11 & 45 & 30 & 1.15 & 0.55 & 0.94 & 1.26 & 1.71 & 1.12 & 1.14 & 1.7 \\
\hline 12 & 60 & 35 & 1.6 & 0.77 & 1.28 & 2.31 & 2.64 & 1.56 & 1.59 & 2.64 \\
\hline 13 & 60 & 35 & 1.92 & 0.96 & 1.62 & 2.59 & 2.91 & 1.87 & 1.91 & 2.96 \\
\hline 14 & 120 & 80 & 4.06 & 2.14 & 3.65 & 10.43 & 8.65 & 3.94 & 4.04 & 8.79 \\
\hline 15 & 60 & 10 & 2.01 & 0.94 & 1.35 & 2.13 & 2.39 & 1.96 & 2.01 & 2.47 \\
\hline 16 & 60 & 20 & 2.11 & 1.02 & 1.61 & 2.36 & 2.68 & 2.06 & 2.11 & 2.78 \\
\hline 17 & 60 & 20 & 2.21 & 1.07 & 1.7 & 2.44 & 2.75 & 2.15 & 2.21 & 2.86 \\
\hline 18 & 90 & 40 & 3.38 & 1.69 & 2.79 & 6.02 & 4.97 & 3.28 & 3.37 & 5.66 \\
\hline 19 & 90 & 40 & 0.1 & 1.66 & 0.08 & 0.19 & 0.17 & 0.1 & 0.11 & 0.19 \\
\hline 20 & 90 & 40 & 0.38 & 1.82 & 0.36 & 0.46 & 0.41 & 0.38 & 0.37 & 0.47 \\
\hline 21 & 90 & 40 & 0.43 & 1.85 & 0.41 & 0.51 & 0.46 & 0.43 & 0.42 & 0.52 \\
\hline 22 & 90 & 40 & 0.47 & 1.87 & 0.45 & 0.56 & 0.49 & 0.47 & 0.47 & 0.56 \\
\hline 23 & 90 & 50 & 0.29 & 1.98 & 0.2 & 0.93 & 0.85 & 0.26 & 0.26 & 0.96 \\
\hline 24 & 420 & 200 & 1.26 & 9.04 & 1.07 & 11.2 & 6.72 & 1.04 & 1.03 & 7.64 \\
\hline 25 & 420 & 200 & -0.15 & 8.42 & 0.07 & 11.4 & -4.94 & -0.30 & 0.02 & 7.28 \\
\hline 26 & 60 & 25 & 0.43 & 1.22 & 0.03 & 1.15 & 1.21 & 0.39 & 0.42 & 1.39 \\
\hline 27 & 60 & 25 & 0.55 & 1.28 & 0.11 & 1.19 & 1.26 & 0.52 & 0.79 & 1.45 \\
\hline 28 & 60 & 20 & 1.02 & 1.44 & 0.29 & 1.24 & 1.33 & 0.98 & 1.21 & 1.57 \\
\hline 29 & 120 & 70 & 3.45 & 3.48 & 1.54 & 6.38 & 4.83 & 3.36 & 3.41 & 5.59 \\
\hline 30 & 200 & 600 & 17.75 & 16.55 & 14.63 & 42.93 & 30.68 & 17.64 & 21.74 & 33.92 \\
\hline 31 & 150 & 70 & 4.63 & 4.3 & 1.97 & 9.42 & -12.34 & 4.5 & 4.67 & 7.57 \\
\hline 32 & 210 & 100 & -2.84 & 6.13 & 2.68 & 16.34 & 10.27 & 6.5 & 6.6 & 12 \\
\hline 33 & 60 & 40 & 2.19 & 1.91 & 1.07 & 1.86 & 1.99 & 2.15 & 2.29 & 2.3 \\
\hline DG6 & 2043.954 & 989.932 & -120.33 & -2.37 & -0.05 & -69.26 & -54.77 & -11.76 & -13.76 & -62.54 \\
\hline DG25 & 695.869 & 521.901 & -21.44 & -15.75 & -0.04 & -19.84 & -11.35 & 0.55 & -1.25 & -12.87 \\
\hline DG31 & 520.808 & 0 & -17.48 & -13.55 & -0.16 & -35.4 & -18.82 & -9.42 & -11.77 & -21.67 \\
\hline & Total loss & & 43.42 & 43.42 & 43.42 & 43.42 & 43.42 & 43.42 & 43.42 & 43.42 \\
\hline
\end{tabular}

Note: P: Active power; Q: Reactive power; DG: Distributed Generator; MLC: Marginal Loss Coefficient Method; BCDM:

Branch Current Decomposition Method; PSMLA: Power summation technique; PR: Pro-Rata method; LA: Loss Allocation. 
marginal method suffers from computational paradox due to the implementation of Jacobian and Hessian matrices in the loss calculation procedure. However, the proposed technique is easy to understand and free from computational complexity.

The Z-bus LA technique [7] assigns negative losses to the customers at DG connected nodes, but positive losses to the DG owners, being unfair from the DG point of view. However, the present scheme not only provides benefits to not only DGOs but also the DGconnected consumers. Further, the Z-bus technique may face difficulty for allocating losses in the overhead RDN due to the singularity of the admittance matrix, but the proposed approach is free from this drawback.

The LA by SM technique [8] is found to be better than $\mathrm{PR}$ and marginal methods and very close to the results of the Z-bus method. However, LA by the present method is found to be better than SM technique. Again, the SM technique allocates a huge amount of loss to the generation units even if their penetrations reduce the power loss of the RDN, which can be considered a significant drawback as compared to the proposed method.

The load demand of the consumer at node 17 is greater than that at node 15 , and it is almost at an equal distance from the source node. Hence, the consumer at bus 17 is assigned greater loss than that at node 15. However, BCDM method [11] allocates less loss to the consumer at node 17 , which is unexpected. Further, BCDM awards more remuneration to the DG at node 16 against DG at node 17 even though it injects less power. However, these inconsistencies are not present in the proposed method.

It can be observed that Jahromi's procedure [17] has become partial for those load buses where DGs are connected. This method allocates zero losses to demands/DGs which are locally injected/consumed by DGs/demands. Thus, the consumers at nodes 15 , 16, and 17 are assigned zero losses because of more generations than demands. Also, some discrepancy in the result of LA between the consumers of nodes 11 and 12 is marked in terms of geographical location and load demand. These difficulties are not found in the case of the proposed LA procedure and the LA between nodes 11 and 12 is observed to be fair.

The LA based on a game theory-based SSV technique [20] is analogous to the present approach, but it suffers computational time complexity and memory burden for large electrical networks.

The method discussed in [23] requires a normalization factor in the final allocation of losses among the end users, whereas the proposed method allocates it without reconciliation. The LA results obtained using this approach are found very close to those obtained by Jahromi's method [17]; hence, the approach also suffers from the same problem of partial LA, as discussed in the method [17]. Moreover, both of the mentioned methods are causing injustice to the DG owner of bus 17 because Jahromi's method allocates zero loss, while the method [23] assigns a penalty of $0.07 \mathrm{~kW}$ to this DG owner. However, the DG owner has been rewarded with the proposed remuneration technique.

Furthermore, in order to verify the performance in terms of the capability to discriminate fair LA, two sets of nodes having equal consumptions, yet in different geographical locations, are identified. At first, a set of two distance nodes 3 and 9 is selected whose difference in LA is calculated and represented in Figure 5. It can be realized that the difference in LA by the present technique is very close to the Z-Bus, SM, BCDM, Jahromi's, and SSV methods. This difference is zero in the case of PR method as it allocates an equal amount of loss to loads of identical demand. The LA of method [23] and marginal methods is quite significant in comparison to the above-discussed LA schemes.

Similarly, to test the performance of two close nodes, a set of nodes 5 and 7 is identified and its difference in LA is presented in Figure 6. Accordingly,

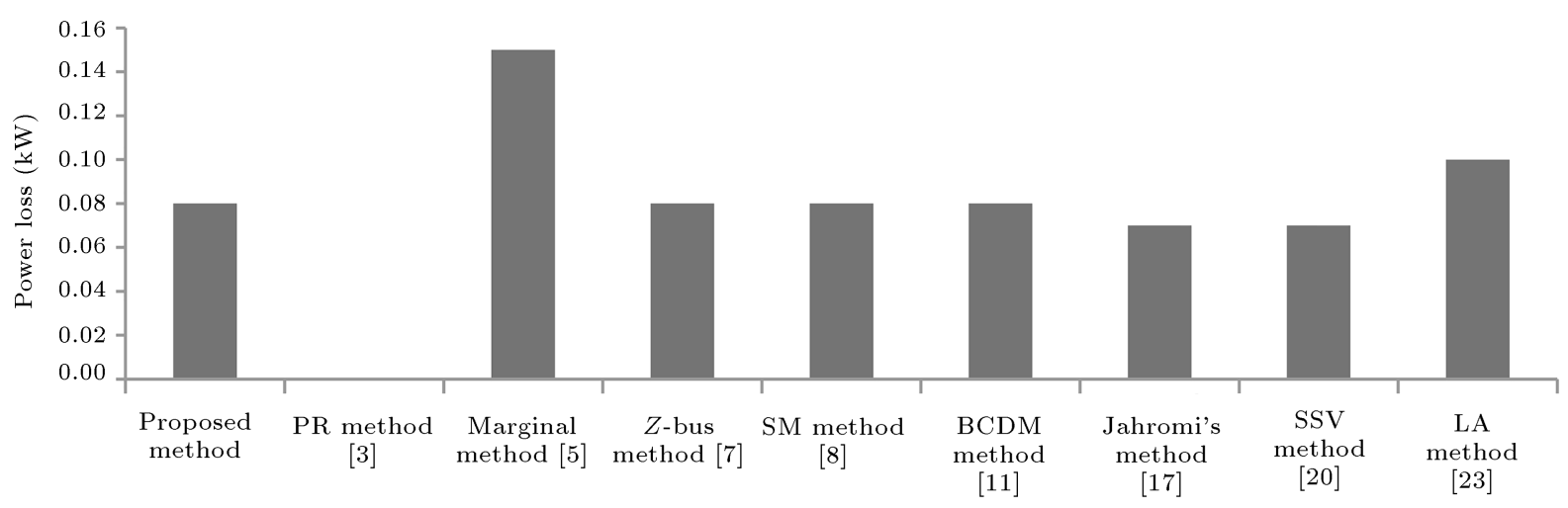

Figure 5. Comparison of difference in Loss Allocation (LA) between nodes 9 and 3 of a 17-bus Radial Distribution Network (RDN) with the existing methods: Pro-Rata (PR), marginal, Z-bus, Succinct Method (SM), Branch Current Decomposition Method (BCDM), Jahromi's, Sequential Shapley Value (SSV), and LA method [23]. 


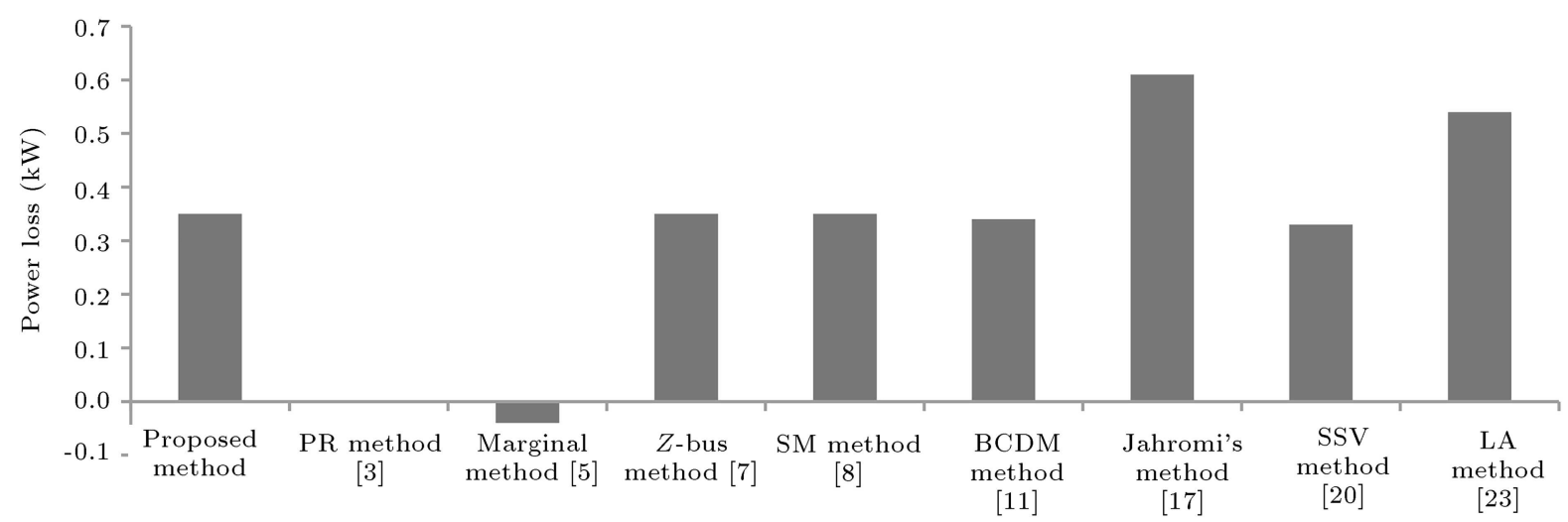

Figure 6. Comparison of difference in Loss Allocation (LA) between nodes 7 and 5 of a 17-bus Radial Distribution Network (RDN) with the existing methods: Pro-Rata (PR), marginal, Z-bus, Succinct Method (SM), Branch Current Decomposition Method (BCDM), Jahromi's, Sequential Shapley Value (SSV), and LA method [23].

the performance of the proposed approach is very close to those of Z-Bus, SM, BCDM, and SSV methods. However, PR scheme assigns an equal amount of loss to both nodes, whereas marginal method allocates greater loss to the consumer at node 5 than that at node 7 , which is undesired. The discrimination between the methods [17] and [23] is higher than those of other methods discussed above. However, the proposed method maintains consistency in both of the scenarios by allocating an adequate amount of loss to the network participants with respect to their load demands and geographical locations in the RDN.

\subsection{Case study II (a 33-bus system)}

A $12.66 \mathrm{kV}, 33$-bus RDN [32] with total active and reactive power of $(3715+\mathrm{j} 2300) \mathrm{KVA}$ is considered for analyzing the effectiveness of the proposed method against other established methods. The line data of the test system are presented in Table 1 . This test system is modified further by connecting three DGs at nodes 6, 25, and 31 for achieving an optimal RDN. The position and size of the DGs have been selected as per the analytical procedure discussed in [33]. The corresponding load and DG data along with the results of LA are provided in Table 3 .

At the load level of $100 \%$, without DGs, the total real power loss of the 33 -bus RDN is found to be $202.67 \mathrm{~kW}$, which is reduced to $43.42 \mathrm{~kW}$ due to the implementation of DGs into the system. Thus, a total loss reduction of $159.25 \mathrm{~kW}$ is noticed due to the penetration of DG units into the system. The power injection of DG at node 6 (DG6) is found to be greater than that of the other two DGs. Out of the other two DGs, the DG at node 25 (DG25) injects greater power than that at node 31 (DG31).

According to Table 3, Marginal Loss Coefficient (MLC) method [5] allocates minimum remuneration to DG6, while BCDM provides DG31 with maximum benefit, which is unexpected. Modified PR method
[18] assigns penalties to DG25 even if there is a total NLR of $159.25 \mathrm{~kW}$ in the system due to DG penetration. Further, it provides more remuneration for DG31 against DG25, whereas DG25 is injecting greater power than DG31. Other established methods allocate more incentives to DG31 against DG25, which is unfair. However, a fair allocation with proper DG remuneration is ensured by the proposed method. The present strategy provides maximum benefits for DG6; out of the other two DGs, it assigns more remuneration to DG25. This remuneration scheme provides all the benefits of loss reduction for the DG units after analyzing their exact contribution to NLR. The proposed technique provides maximum benefits for the DG owners, whereas BCDM [11] delivers maximum spatial cross-subsidies to consumers. The loss assigned to the heavily loaded consumer connected at node 30 is minimum (i.e., $14.63 \mathrm{~kW}$ ) by BCDM method and maximum (i.e., $42.93 \mathrm{~kW}$ ) by PSMLA method [12]. However, the present method allocates it fairly (i.e., $17.75 \mathrm{~kW}$ ) with due consideration of the position of the nearest DG, load demand, and its physical location. Ghaemis's method [19] allocates large amounts of losses to the heavily loaded buses (buses 7, 8, 14, and 30) equal to those of PSMLA and Proportional [10] techniques and simultaneously, it assigns huge negative losses to the DG-connected load points. However, the present method takes care of these issues. The voltagebased LA [18] and MLC [5] offer rewards to the DG owners moderately, whereas the proportional method [10] awards more remuneration to the DG owners than the method discussed above. Yet, the entire benefit is rewarded by the present approach.

Furthermore, to verify the performances of the methods in the case of geographical locations, two sets of nodes with equal demands are identified whose difference in LA is calculated and presented in Figures 7 and 8 for comparison with the existing techniques. Firstly, a set of the two distance nodes 3 and 22 


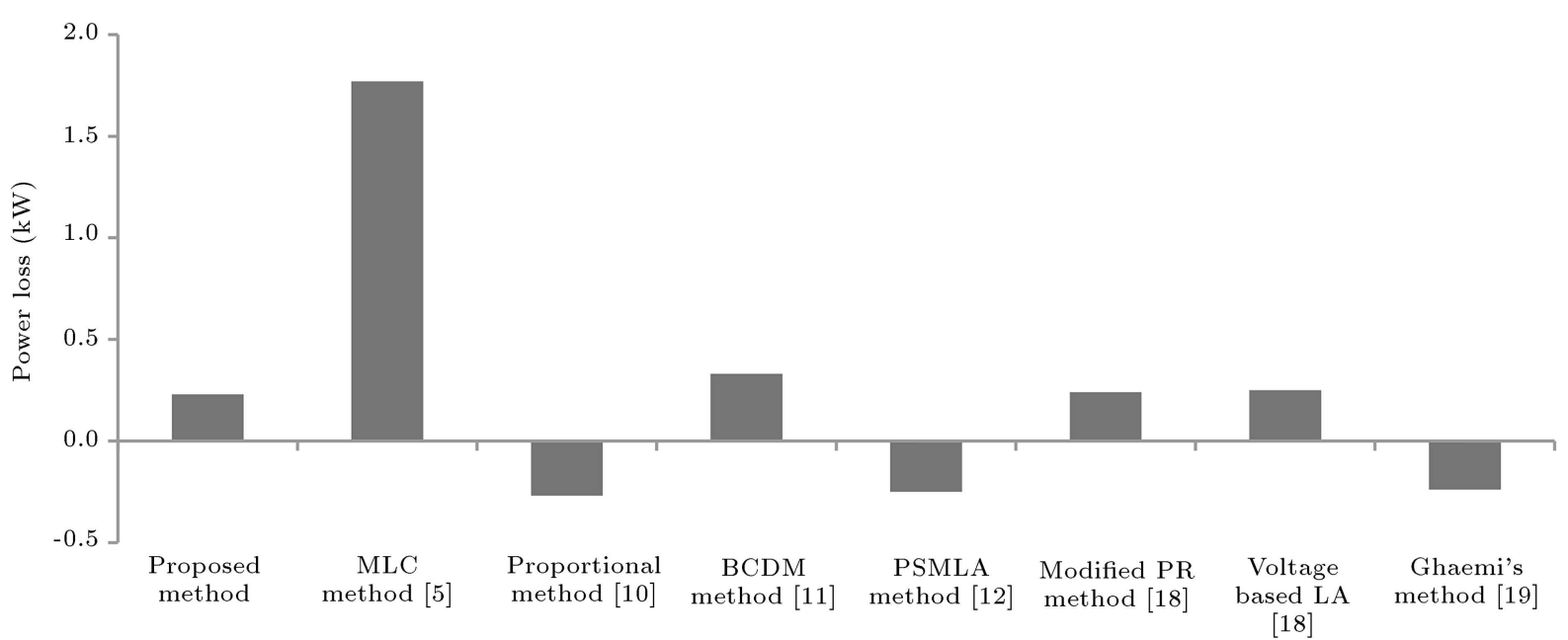

Figure 7. Comparison of difference in Loss Allocation (LA) between nodes 22 and 3 of a 33-bus Radial Distribution Network (RDN) with the existing methods: Marginal Loss Coefficient (MLC), proportional, Branch Current Decomposition Method (BCDM), power summation technique (PSMLA), modified Pro-Rata (PR), voltage based LA method [18], and Ghaemi's method [19].

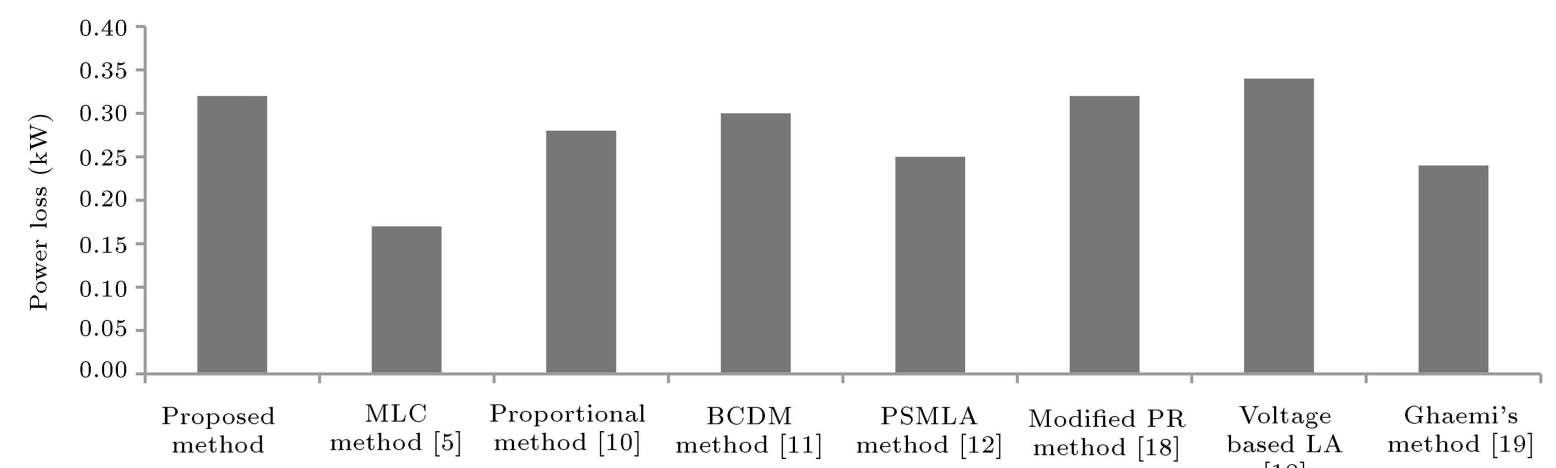

[18]

Figure 8. Comparison of difference in Loss Allocation (LA) between nodes 10 and 9 of a 33-bus Radial Distribution Network (RDN) with the existing methods: Marginal Loss Coefficient (MLC), proportional, Branch Current Decomposition Method (BCDM), power summation technique (PSMLA), modified Pro-Rata (PR), voltage based LA method [18], and Ghaemi's method [19].

is selected where node 3 is electrically close to the substation bus. Hence, the consumer at node 22 should receive greater loss than the consumer at Bus 3 . However, based on Figure 7, it can be verified that PSMLA, Proportional, and Ghaemi's methods allocate losses to these consumers in a reverse way. However, the proposed method and other remaining established methods assign losses in proper order. It can also be observed that the discrimination of LA through the present scheme is very close to that in the case of BCDM, Proportional, modified PR, and voltage-based LA methods, whereas it is quite significant in MLC.

Moreover, the consumers at nodes 9 and 10 are having the same load demands and are electrically close to each other. It can be verified from Figure 8 that the present approach, BCDM, modified PR, and voltage-based LA [18] methods treat these consumers identically with better LA as compared to PSMLA,
Proportional, and Ghaemi's methods. However, the discrimination of LA between the customers of the same ratings placed close to each other is better for the proposed method, while it is poor in the case of MLC technique. Thus, it is verified that the present LA procedure allocates losses with due consideration of the network topology of the RDN. Again, in order to investigate the LA results with regard to power factor (p.f.), three heavily loaded end users connected at nodes 30, 31, and 32 are identified. The p.f. of a consumer at node 30 (p.f., 0.32 lagging) is found quite poor compared to that of consumers at nodes 31 and 32 (p.f., 0.9 lagging). Of note, the load point with poor p.f. has been assigned more loss than the other two consumers, which is fair and justified. Further, the efficiency of the proposed method is also tested in larger networks using two test systems, i.e., 69-bus RDN [23] and 136-bus RDN [34], providing 
total LA of $225 \mathrm{~kW}$ and $320.36 \mathrm{~kW}$ in the base case with computational times of 0.0193 second and 0.1943 second, respectively. In light of the above discussions, the proposed LA strategy is found more suitable and efficient for practical implementation than the other methods discussed.

Since there are more and more renewable energy sources in distribution networks, the output of DGs is actually time-varying and a fair amount of uncertainty is also involved, which cannot be regarded as constant load and therefore, not considered in this paper due to the limited research scope. However, the LA approach proposed in this paper can be effectively applied as a building block in the scenario-based approach to capture the uncertainties associated with DGs and loads.

\section{Conclusion}

This study developed a new active power Loss Allocation (LA) method by eliminating the impact of cross term mathematically from the loss formulation. For LA with Distributed Generations (DGs), the DGs were modeled as negative power injections and included in the LA process. Moreover, LA was not involved in any over-recovery of losses, hence no normalization of the allocated losses required. The effectiveness of the proposed technique was verified in the case of two test systems in the presence of DGs. The results obtained were more promising than other established methods. It was investigated that some of the established methods (PR [3], Marginal [5], Z-Bus [7], SM [8], Jahromi's [17], Modified PR [18], and Method [23]) assigned penalties to the Distributed Generator Owners (DGOs), even if their penetration reduced system loss, which is unfair. Also, some existing techniques diverted a part of Network Loss Reduction (NLR) as cross-subsidies to the consumer side even though their impact on NLR is insignificant. However, the proposed approach allocates all the benefits of NLR to the DGOs. Hence, it is more accurate and may be suggested for practical implementation.

\section{Nomenclature}

$\begin{array}{ll}P & \text { Real power }(\mathrm{kW}) \\ Q & \text { Reactive power (kVAR) } \\ R & \text { Resistance }(\Omega) \\ a & \text { Node number } \\ V_{s} & \text { Sending end voltage of branch } j j \\ V_{a} & \text { Voltage of node } a \\ a d b[] & \text { Array used to store adjacent buses } \\ m f[] & \text { relating to each node of the RDN } \\ & \text { Array used to store initial memory } \\ & \text { location of the adjacent buses relating } \\ & \text { to each node of the RDN in array } a d b[]\end{array}$

\begin{tabular}{|c|c|}
\hline$m f s[]$ & $\begin{array}{l}\text { Array used to store initial memory } \\
\text { location of the subsequent buses } \\
\text { relating to each branch of the RDN in } \\
\text { array } s b[]\end{array}$ \\
\hline$p b[]$ & $\begin{array}{l}\text { Array used to store previous buses } \\
\text { relating to each node of the RDN }\end{array}$ \\
\hline$s$ & $\begin{array}{l}\text { Represents the memory location in } \\
\text { array } a d b[]\end{array}$ \\
\hline$S_{L a}$ & $\begin{array}{l}\text { Net complex power connected at node } \\
a\end{array}$ \\
\hline$Q_{L a}$ & $\begin{array}{l}\text { Net reactive power connected at node } \\
a\end{array}$ \\
\hline $\operatorname{PLoss}(j j)$ & Power loss of branch $j j$ \\
\hline$P \operatorname{Loss}(j j, a)$ & $\begin{array}{l}\text { Power loss of branch } j j \text {, which is } \\
\text { assigned to node } a\end{array}$ \\
\hline TPLoss $(a)$ & $\begin{array}{l}\text { Total Power loss assigned to the } \\
\text { participant of node } a\end{array}$ \\
\hline TPLoss & Total Power loss of the RDN \\
\hline$P_{d g}(p)$ & $\begin{array}{l}\text { Power loss of the RDN without } p \text { th } \\
\text { DG unit }\end{array}$ \\
\hline $\operatorname{In} n_{d g}(p)$ & $\begin{array}{l}\text { Contribution of } p \text { th DG unit towards } \\
\text { system loss reduction }\end{array}$ \\
\hline $\operatorname{Diff}\left(I n_{d g}\right)$ & $\begin{array}{l}\text { Difference between actual and } \\
\text { calculated value of DG remuneration }\end{array}$ \\
\hline$f I n_{d g}(p)$ & $\begin{array}{l}\text { Final remuneration awarded to the } p \text { th } \\
\text { DG owner }\end{array}$ \\
\hline$N B$ & Total number of nodes in the RDN \\
\hline$N B R$ & Total number of branches in the $\mathrm{RDN}$ \\
\hline$X$ & Reactance $(\Omega)$ \\
\hline$j j$ & Branch number \\
\hline$V_{r}$ & Receiving end voltage of branch $j j$ \\
\hline$I(j j)$ & Current of branch $j j$ \\
\hline$s b[]$ & $\begin{array}{l}\text { Array used to store subsequent buses } \\
\text { relating to each branch of the RDN }\end{array}$ \\
\hline
\end{tabular}

$m t$ [] Array used to store final memory location of the adjacent buses relating to each node of the RDN in array $a d b[$ ]

$m t s[] \quad$ Array used to store final memory location of the subsequent buses relating to each branch of the RDN in array $s b[]$

$n s b[] \quad$ Array used to store information of total subsequent buses relating to each branch of the RDN

$x$

$P_{L a}$

$I_{L a}$

$*$

$P_{a d g}$

$P_{p d g}$
The memory location in array $s b[]$

Net real power connected at node $a$

Load current at node $a$

Complex conjugate operator

Power loss of the RDN without DGs

Power loss of the RDN in the presence of all DGs 


$\begin{array}{ll}p & \text { DG number } \\ P_{d g s} & \text { Power loss reduction due to DGs } \\ N_{d g} & \text { Total number of DG units connected } \\ & \text { in the RDN } \\ T I n_{d g} & \text { Calculated value of DG remuneration } \\ f T I n_{d g} & \text { Final remuneration awarded to the DG } \\ & \text { owners }\end{array}$

\section{References}

1. Abdelkader, S. "Transmission loss allocation in a deregulated electrical energy market", Electric Power Systems Research, 76(11), pp. 962-967 (2006).

2. Carpaneto, E., Chicco, G., and Akilimali, J.S. "Characterization of the loss allocation techniques for radial systems with distributed generation", Electric Power Systems Research, 78(8), pp. 1396-1406 (2008).

3. Gonzalez, J.J. and Basagoiti, P. "Spanish power exchange market and information system. Design concept, and operating experience", IEEE Power Industry Computer Application Conf., Santa Clara, CA, pp. 245-252 (1999).

4. Pan, J., Teklu, Y., Rahman, S., et al. "Review of usagebased transmission cost allocation methods under open access", IEEE Transactions on Power Systems, 15(4), pp. 1218-24 (2000).

5. Mutale, J., Strbac, G., Curcic, S., et al. "Allocation of losses in distribution system with embedded generation", IEE Proceedings-Generation, Transmission and Distribution, 147(1), pp. 7-14 (2000).

6. Galiana, F.D., Conejo, A.J., and Kockar, I. "Incremental transmission loss allocation under pool dispatch", IEEE Transactions on Power Systems, 17(1), pp. 2633 (2002).

7. Conejo, A.J., Galiana, F.D., and Kockar, I. "Z-bus loss allocation", IEEE Transactions on Power Systems, 16(1), pp. 105-110 (2001).

8. Fang, W.L. and Ngan, H.W. "Succinct method for allocation of network losses", IEE Proceedings-Generation, Transmission and Distribution, 149(2), pp. 171-174 (2002).

9. Costa, P.M. and Matos, M.A. "Loss allocation in distribution networks with embedded generation", IEEE Transactions on Power Systems, 19(1), pp. 384-389 (2004).

10. Bialek, J.W. and Kattuman, P.A. "Proportional sharing assumption in tracing methodology", IEE Proceedings-Generation, Transmission and Distribution, 151(4), pp. 526-532 (2004).

11. Carpaneto, E., Chicco, G., and Akilimali, J.S. "Branch current decomposition method for loss allocation in radial distribution systems with distributed generation", IEEE Transactions on Power Systems, 21(3), pp. 1170-1179 (2006).
12. Atanasovski, M. and Taleski, R. "Power summation method for loss allocation in radial distribution networks with DG", IEEE Transactions on Power Systems, 26(4), pp. 2491-2499 (2011).

13. Atanasovski, M. and Taleski, R. "Energy summation method for loss allocation in radial distribution networks with DG", IEEE Transactions on Power Systems, 27(3), pp. 1433-1440 (2012).

14. Savier, J.S. and Das, D. "Impact of network reconfiguration on loss allocation of radial distribution systems", IEEE Transactions on Power Delivery, 22(4), pp. 2473-2480 (2007).

15. Savier, J.S. and Das, D. "An exact method for loss allocation in radial distribution systems", International Journal of Electrical Power and Energy Systems, 36(1), pp. 100-106 (2012).

16. Mishra, S. and Das, D. "A novel active power loss allocation scheme for unbalanced radial power distribution system", International Review of Electrical Engineering, 3(3), pp. 543-550 (2008).

17. Ghofrani-Jahromi, Z., Mahmoodzadeh, Z., and Ehsan, M. "Distribution loss allocation for radial systems including DGs", IEEE Transactions on Power Delivery, 29(1), pp. 72-80 (2014).

18. Jagtap, K.M. and Khatod, D.K. "Loss allocation in distribution network with distributed generations", IET Generation, Transmission \& Distribution, 9(13), pp. 1628-1641 (2015).

19. Ghaemi, S. and Zare, K. "Loss allocation in restructured radial distribution networks considering the contractual power", IET Generation, Transmission \& Distribution, 11(6), pp. 1389-1397 (2016).

20. Sharma, S. and Abhyankar, A.R. "Loss allocation of radial distribution system using Shapley value: A sequential approach", International Journal of Electrical Power \& Energy Systems, 88, pp. 33-41 (2017).

21. Jagtap, K.M. and Khatod, D.K. "Novel approach for loss allocation of distribution networks with DGs", Electric Power System Research, 143, pp. 303-311 (2017).

22. Kashyap, S.S. and De, M. "Loss allocation and loss minimisation for radial distribution system including DGs", IET Renewable Power Generation, 11(6), pp. 806-818 (2017).

23. Khosravi, M., Monsef, H., and Aliabadi, M.H. "Loss allocation in distribution network including distributed energy resources (DERs)", International Transactions on Electrical Energy Systems, 28(6), p. e2548 (2018).

24. Kumar, P., Gupta, N., Niazi, K.R., et al. "Cross-term decomposition method for loss allocation in distribution systems considering load power factor", Electric Power Components and Systems, 46(2), pp. 218-229 (2018).

25. Ghosh, S. and Das, D. "Method for load-flow solution of radial distribution networks", IEE ProceedingsGeneration, Transmission and Distribution, 146(6), pp. 641-648 (1999). 
26. Eminoglu, U., Gozel, T., and Hocaoglu, M.H. "DSPFAP: distribution systems power flow analysis package using MATLAB graphical user interface (GUI)", Comp. Appl. Engg. Edu., 18(1), pp. 1-13 (2010).

27. Dugan, R.C. "Challenges in considering distributed generation in the analysis and design of distribution systems", Proc. IEEE PES Gen. Meet., pp. 1-8 (2008).

28. Choi, J-H. and Kim, J-C. "Advanced voltage regulation method at the power distribution systems interconnected with dispersed storage and generation systems", IEEE Trans. Pow. Deliv., 15(2), pp. 691696 (2000).

29. Mishra, S., Das, D., and Paul, S. "A simple algorithm for distribution system load flow with distributed generation", Proc. ICRAIE-2014, May 09-11, Jaipur, India (2014).

30. Teng, J.H. "Modeling distributed generations in three phase distribution load flow", IET Gen. Trans. Distrib., 2(3), pp. 330-340 (2008).

31. Kumar, P., Gupta, N., Niazi, K.R., et al. "Branch current decomposition method for loss allocation in contemporary distribution systems", International Journal of Electrical Power \& Energy Systems, 99, pp. 134145 (2018).

32. Baran, M.E. and Wu, F.F. "Network reconfiguration in distribution systems for loss reduction and load balancing", IEEE Transactions on Power Delivery, 4(2), pp. 1401-1407 (1989).

33. Naik, S.N.G. and Khatod, D.K. "Analytical approach for optimal siting and sizing of distributed generation in radial distribution networks", IET Generation, Transmission \& Distribution, 9(3), pp. 209-220 (2015).
34. Zin, A.A.M., Ferdavani, A.K., Khairuddin, A.B., et al. "Reconfiguration of radial electrical distribution network through minimum-current circular-updatingmechanism method", IEEE Transactions on Power Systems, 27(2), pp. 968-974 (2012).

\section{Biographies}

Ambika Prasad Hota received his BE degree in Electrical Engineering in 2005 from Biju Patnaik University of Technology, India and his MTech degree in Electrical Engineering in 2013 from Indian Institute of Technology, Kharagpur, India. $\mathrm{He}$ is currently pursuing his $\mathrm{PhD}$ program in International Institute of Information Technology, Bhubaneswar, India in Electrical Engineering with emphasis on Smart Grid management systems. His research interests include operation and control of power systems, renewable energies, network modeling, and smart grid.

Sivkumar Mishra received his BE degree in Electrical Engineering from Malaviya Regional Engineering College, Jaipur affiliated to University of Rajasthan in 1995, MTech degree from Indian Institute of Technology, Kharagpur, India, and $\mathrm{PhD}$ degree from Jadavpur University, India, respectively. He is currently working as an Associate Professor at the Department of Electrical Engineering, Center for Advance Post Graduate Studies (CAPGS), Biju Patnaik University of Technology (BPUT), Odisha, Rourkela, India. His research interests include electrical Power distribution system analysis, distributed generation and micro Grid, smart grid, and application of IOT and big data analytics in electrical power systems. 